\title{
Impact of parathyroidectomy on cardiovascular outcomes and survival in chronic hemodialysis patients with secondary hyperparathyroidism. A retrospective study of 50 cases prior to the calcimimetics era
}

\author{
Giovanni Conzo ${ }^{1 *}$, Alessandra F Perna², Vincenzo Savica ${ }^{3}$, Antonietta Palazzo $^{1}$, Cristina Della Pietra',
} Diego Ingrosso ${ }^{4}$, Ersilia Satta², Giovambattista Capasso², Luigi Santini ${ }^{1}$, Giovanni Docimo ${ }^{1}$

From 26th National Congress of the Italian Society of Geriatric Surgery

Naples, Italy. 19-22 June 2013

\begin{abstract}
Background: In chronic hemodialysis patients with secondary hyperparathyroidism, pathological modifications of bone and mineral metabolism increase the risk of cardiovascular morbidity and mortality. Parathyroidectomy, reducing the incidence of cardiovascular events, may improve outcomes; however, its effects on long-term survival are still subject of active research.

We compared, in hemodialysis patients, the results of parathyroidectomy, in terms of cardiovascular outcomes and mortality, with those present in patients following medical treatment only, prior to the diffusion of calcimimetics.

Methods: From January 2004 to December 2006, 30 hemodialysis patients, affected by severe and unresponsive secondary hyperparathyroidism, underwent parathyroidectomy - 15 total parathyroidectomy and 15 total parathyroidectomy + subcutaneous autoimplantation. During a 5-year follow-up, patients did not receive a renal transplantation and were evaluated for biochemical modifications and major cardiovascular events - death, cardiovascular accidents, myocardial infarction and peripheral vascular disease. Results were compared with those obtained in a control group of 20 hemodialysis patients, affected by secondary hyperparathyroidism, and refusing surgical treatment, and following medical treatment only.

Results: The groups were comparable in terms of age, gender, dialysis vintage, and comorbidities. Postoperative cardiovascular events were observed in 18/30 - 54\% - surgical patients and in 4/20 - 20\%- medical patients, with a mortality rate respectively of $23.3 \%$ in the surgical group vs. $15 \%$ in the control group. Parathyroidectomy was not associated with a reduced risk of cardiovascular morbidity and survival rate was unaffected by surgical treatment.

Conclusions: In secondary hyperparathyroidism hemodialysis patients affected by severe cardiovascular disease, surgery did not modify cardiovascular morbidity and mortality rates. Therefore, in secondary hyperparathyroidism hemodialysis patients, resistant to medical treatment, only an early indication to calcimimetics, or surgery, in the
\end{abstract}

\footnotetext{
* Correspondence: giovanni.conzo@unina2.it

'Department of Anaesthesiologic, Surgical and Emergency Sciences - VII Division of General and Endocrine Surgery-Second University of Naples Italy

Full list of author information is available at the end of the article
} 
initial stage of chronic kidney disease - mineral bone disorders, may offer a higher long-term survival.

Further studies will be useful to clarify the role of secondary hyperparathyroidism in determining unfavorable

cardiovascular outcomes and mortality in hemodialysis population.

\section{Introduction}

Incidence of secondary hyperparathyroidism (2HPT) in the setting of chronic kidney disease-mineral bone disorder (CKD-MBD), increases with dialysis vintage, and, prior to the calcimimetic era, parathyroidectomy (PTx) became necessary in $15 \%$ of cases after 10 years, which rose to $38 \%$ after 20 years [1]. According to PA Decker et al., an intervention was required in $2.5 \%$ of dialysis patients a year [2]. From the analysis of medical treatment results, it emerged that only about half of the patients were controlled in terms of serum calcium $(\mathrm{Ca})$, serum phosphate $(\mathrm{P}), \mathrm{Ca} \times \mathrm{P}$ product and intact parathyroid hormone (iPTH)[3]. Recently, calcimimetics, well tolerated allosteric modulators of the calcium-sensing receptor, inhibiting glandular hyperplasia and significantly reducing circulating iPTH levels without exacerbating hyperphosphatemia or hypercalcemia, have been shown to exert a major beneficial impact on 2HTP management. They determine a reduction of fractures, hospitalizations and of PTxs in CKDMBD population $[4,5]$. However, $R$ Narayan et al. reported that PTx is more cost effective than cinacalcet in the majority of patients, with the exception of those who are either at high mortality risk, or those who would expect to receive a kidney transplantation in the near future [6]. 2HPT has a negative effect on quality of life under many respects, and induces a higher mortality rate, particularly due to the onset of premature cardiovascular complications, which is associated with vascular calcifications and hypertension. In addition, anemia, at times resistant to erythropoiesis-stimulating agents, becomes a risk factor for unfavorable cardiovascular outcomes $[7,8]$. The risk for cardiovascular events is increased by 10 - to 30 -fold among HD patients compared with the general population [9]. It has been demonstrated that at PTH levels $>495 \mathrm{pg} / \mathrm{ml}$ there is a $25 \%$ increased risk of mortality [10], and the response to vitamin D is reduced by $50 \%$ at PTH > $750 \mathrm{pg} / \mathrm{ml}$ [11]. Therefore, early surgery could offer an improved quality of life and possibly a higher long-term survival rate. KDIGO parameters modified the National Kidney Foundation (NKF) guidelines [12], by referring to local normal laboratory ranges for $\mathrm{Ca}$, phosphorus and PTH levels, which should be between 2 and 9 times the normal range [13]. Successful surgical treatment often results in a dramatic reduction of iPTH levels, relieving the patient from clinical symptoms [14-17], and different papers showed that PTX could also improve mortality and cardiovascular morbidity [18-23].
With the aim to analyze this issue, we tested the impact of surgery on cardiovascular outcomes and survival in 50 2HPT HD patients, after long-term follow-up. Pre and postoperative cardiovascular status and postoperative outcomes were evaluated in 30 patients submitted to PTx and compared to $20 \mathrm{HD}$ patients refusing surgery. In both populations, calcimimetics were not utilized, and indications to surgical procedure were set according to both K/DOQI 2003 guidelines and Y Tominaga et al. [12,17].

\section{Materials and methods Study design}

A retrospective cohort study, in a group of $50 \mathrm{HD}$ patients with severe $2 \mathrm{HPT}$, unresponsive to medical treatment, selected for PTx, and addressed to our Institution from regional HD centers, was performed. Renal transplantation was considered criteria of exclusion. iPTH levels $>53-84$, $8 \mathrm{pmol} / \mathrm{L}$, serum $\mathrm{P}$ level $>2,09 \mathrm{mmol} / \mathrm{l}$, US enlarged parathyroid glands $\left(>1 \mathrm{~cm}\right.$ or $\left.>500 \mathrm{~mm}^{3}\right)$ and persisting clinical symptoms, six months after medical therapy, were considered the main criteria for PTx. 30 patients accepted to undergo surgical treatment (surgical group) and 20 patients, refusing surgery, were considered as medical control group. 4 parathyroid glands at least were removed in every case eligible for the study. Cardiovascular disease was defined as presence of hypertension, peripheral artery disease, electrocardiogram (ECG) signs of cardiac hypertrophy, ultrasound (US) cardiac valves calcification, ventricular hypertrophy, arrhythmia, and coronary or cerebrovascular disease. According to P Raggi et al. [24], US valvular calcification was considered as the hallmark of arterial wall calcification in identifying patients affected by severe cardiovascular disease, and an unfavorable prognostic factor, linked to a higher mortality risk. Anemia was evaluated according to the Royal College of Physicians (UK) National Clinical Guideline Centre [25]. During 60 months follow-up, cardiovascular outcomes and survival were evaluated. Mortality data were available trough December 2011. Major cardiovascular events - heart failure, myocardial infarction, peripheral vascular disease and stroke - were the primary end-points, while death was the second end-point.

\section{Surgical group}

Data were retrospectively collected from 30 consecutive patients (110" and 19 \%), affected by $2 \mathrm{HPT}$ of CKD, on standard three-weekly HD, and submitted to PTx 
between January 2004 and January 2006. All patients gave informed consent to participate in the study. Preoperative medical treatment consisted in phosphate chelators (Ca carbonate, sevelamer, lanthanum carbonate), dialysis baths with various $\mathrm{Ca}$ concentrations, vitamin D and its analogues. Antihypertensive drugs were used in $22 / 30$ patients $(73.3 \%)$. The erythropoiesis stimulating agents (ESA) treatment regimen consisted in three-weekly recombinant human ESA (alpha-erythropoietin) injections - $5.200 \pm 3824.48 \mathrm{IU}$, in $29 / 30$ patients. $1 / 30$ patients were treated with alpha darbopoetin 30 (30 $\mu \mathrm{g} /$ every 15 days). Ptx was considered successful when postoperative iPTH level was $<26.52$ $\mathrm{pmol} / \mathrm{L}$. The 1.06-6.89 $\mathrm{pmol} / \mathrm{L}$ range was taken as reference of normal iPTH level based on which eu(1.06-6.89), hypo- $(<1.06)$, aparathyroidism (0) and persistence or relapse $(>6.89)$ of disease were determined. Hypocalcemia was considered to be present when serum calcium was $<1.99 \mathrm{mmol} / \mathrm{L}$ (normal value $=2.09$ $2.54 \mathrm{mmol} / \mathrm{L}$ ). High-resolution neck ultrasonography, ear, nose and throat (ENT) examination, technetium$99 \mathrm{~m}$-sestamibi scintigraphy of the neck and mediastinum, were the main preoperative diagnostic procedures. 12-lead ECG and epiaortic 2-dimensional and color doppler transthoracic echocardiogram, by experienced in-center cardiologists, and peripheral artery color doppler ultrasonography examination were pre and postoperatively performed. Cardiac valves calcification was evaluated according to Wong [26]. iPTH, Ca, P, alkaline phosphatase (ALP) and $\mathrm{FT}_{3}, \mathrm{FT}_{4}, \mathrm{TSH}$, thyroglobulin were measured along with fine needle biopsy of the thyroid nodules; all blood samples were obtained before dialysis. The Liaison ${ }^{\mathbb{B}}$ NTact ${ }^{\mathbb{B}} \mathrm{PTH}$ Assay (DiaSorin IncStillwater, MN, USA), based on chemiluminescence immunoassay (CLIA), was used for the quantitative determination of iPTH (Coefficient of variation: CV\% intra assay 1.7-3.7; CV\% inter assay 2.6-5.9; limit of detection $0.07 \mathrm{pmol} / \mathrm{L}$ ). Indications to surgical procedure were set according to both K/DOQI 2003 guidelines and Y Tominaga et al. [12,17]. Regarding the surgical procedures, 15 patients underwent total parathyroidectomy (TP) and another 15, awaiting renal transplantation, underwent total parathyroidectomy with autotransplantation (TPai) of 9-15 fragments of nonnodular glandular tissue, in 3 subcutaneous pockets of the non-dominant forearm. In 12 out of 30 patients (40\%) with thyroid gland disease, 8 total thyroidectomy and 4 hemithyroidectomy procedures were performed. In all cases, 4 at least parathyroid glands were removed (the nature of the tissue was confirmed via intraoperative histological examination). Only in a few cases, a HD treatment was required immediately after surgery, due to an electrolyte imbalance. The majority of patients required intravenous administration of calcium, due to postoperative hypocalcemia. Patients who underwent autoimplantation completed long-term follow-up monitoring of iPTH from the implantation site and from the contralateral arm, in order to evaluate gradients.

\section{Medical group}

During the same years, 20 patients, ( $80^{*}$ and 12 \%), evaluated by a similar preoperative work-up, in which comparable laboratory and clinical criteria for PTx were present (aggressive 2HPT unresponsive to medical therapy), refused surgery for various reasons and were conservatively managed. Medical treatment consisted in phosphate chelators with sevelamer hydrochloride 3200$4000 \mathrm{mg} \pm 1000$ in $10 / 20$ (50\%) of patients, Vitamin D in 10/20, (50\%). Aluminum salts were used in 1 patient and finally calcium carbonate was used in 10 patients. Patients were on three-weekly recombinant human ESA (alpha erythropoietin) injection, 6000 UI in 10/20 patients; $5 / 20$ patients were treated with alpha darbopoietin $60 \mathrm{mcg}$ every week, and 5 with darbopoietin $80 \mathrm{mcg}$ every 15 days. Antihypertensives were used in $60 \%$ of patients. Every occurrence of a major cardiovascular event and death was evaluated during a 60 months follow-up.

\section{Statistics}

Data were reported as the mean \pm standard error of the mean (SEM). A paired $t$ Student test was performed. The log-rank Mantel-Cox test and the Gehan-BreslowWilcoxon test were used to calculate survival. All calculations were performed using the software package GraphPad Prism, Version 5.0 for Windows (GraphPad Software, San Diego, CA, USA). Statistical significance is considered at $\mathrm{p}<0.05$.

\section{Results}

\section{Surgical groupDemographics}

Patient mean age was $51.5 \pm 10.89$ years, and mean dialysis vintage was $12.93 \pm 8$ years. Mean preoperative iPTH was $142.08 \pm 64.01 \mathrm{pmol} / \mathrm{l}$, and mean serum calcium level was $2.50 \pm 0.45 \mathrm{mmol} / \mathrm{l}$ (Table 1). All patients reported diffuse pruritus, arthromyalgia and mood alterations, while the incidence of baseline cardiovascular pathologies is reported in Table 2. No case of calciphylaxis was reported. Twelve patients (40\%) suffered from coexisting thyroid pathology. None of them had iron deficiency or external blood loss and a mild or moderate anemia (Hb level $7-<12 \mathrm{gr} / \mathrm{dl}$ ) was observed (Table 1).

\section{Surgical outcomes}

TP and TPai were followed by comparable functional outcomes. Surgical treatment produced a benefit in terms of itching, a substantial improvement in clinical 
Table 1 Characteristics of patients

\begin{tabular}{|c|c|c|c|}
\hline & $\begin{array}{l}\text { Surgical } \\
\text { group }\end{array}$ & $\begin{array}{l}\text { Medical } \\
\text { group }\end{array}$ & $\begin{array}{l}\mathrm{p} \\
\text { value }\end{array}$ \\
\hline Age* (years) & $51.5 \pm 10.89$ & $55 \pm 11.20$ & 0.75 \\
\hline Female (\%) & 63.3 & 60 & n.s. \\
\hline Dialysis vintage* (years) & $12.9 \pm 8$ & $10 \pm 1.96$ & n.s. \\
\hline $\mathrm{iPTH}^{*}(\mathrm{pmol} / \mathrm{L})$ & $142.08 \pm 64.01$ & $102.94 \pm 32.51$ & 0.03 \\
\hline $\mathrm{Ca}^{*}(\mathrm{mmol} / \mathrm{L})$ & $2.5 \pm 0.45$ & $2.4 \pm 0,65$ & n.s. \\
\hline Anemia (\%) $(\mathrm{Hb} 7-<12 \mathrm{gr} / \mathrm{dl})^{* *}$ & 100 & 100 & n.s. \\
\hline ESA use (\%) & 100 & 100 & n.s. \\
\hline \multicolumn{4}{|c|}{$\begin{array}{l}\text { *All data were expressed as mean } \pm \text { standard deviation; } \mathrm{p}<0.05 \text { was } \\
\text { considered statistically significant. }\end{array}$} \\
\hline \multicolumn{4}{|c|}{$\begin{array}{l}{ }^{* *} \text { Classification according to the Royal College of Physicians (UK) National } \\
\text { Clinical Guideline Centre }\end{array}$} \\
\hline \multicolumn{4}{|c|}{ ESA = Erythropoiesis-stimulating agent } \\
\hline
\end{tabular}

osteoarticular symptoms as well as in mood patterns first, and later in sleep disorders [14-16], an increase in muscular strength, which were associated to a statistically significant reduction in PTH levels (Figure 1), ESA need and improvement of $\mathrm{Hb}$ levels. With regard to twelve-months Hb levels, $26 / 30$ pts $(86.6 \%)$ showed a significant increase and 5 (19.2\%) of them had an $\mathrm{Hb}$ level $>12 \mathrm{gr} / \mathrm{dl}$. No significant variations were reported in $4 / 30$ pts (13.3\%).

Regarding the postoperative ESA dosage, $27 / 30$ pts (90\%) did not need drug treatment, whilst $3 / 30 \mathrm{pts}$ $(10 \%)$ needed a lower dosage. No significant peri- or postoperative complications were observed. None of the patients was found to be aparathyroid (Table 3). Eighteen patients $(60 \%)$ required intravenous postoperative administration of calcium gluconate due to hypocalcemia, which was occasionally severe, with a minimum value of $1.42 \mathrm{mmol} / \mathrm{L}$, but was never associated with hypocalcemic seizures. The definitive histological examination confirmed the hyperplasia of the removed glands; 2 patients $(6.6 \%)$ had 5 hyperplastic glands; 8 patients (26.6\%) had an associated multinodular goiter, 2 (6.6\%) an adenomatous goiter and $2(6.6 \%)$ a papillary carcinoma. Table 3 shows immediate (on postoperative day 1 ) and long term TP-TPai functional results. After one year, Computed Bone Mineralometry and skeletal $\mathrm{x}$-rays showed a clear regression of osteodystrophy in all

Table 2 Incidence of base-line cardiovascular pathologies (\%)

\begin{tabular}{lll}
\hline & Surgical group & Medical group \\
\hline Congestive heart failure & 3.3 & 10 \\
\hline Coronary disease & 3.3 & 10 \\
\hline Myocardial infarction & 13.3 & 5 \\
\hline Cardiac arrhythmias & 16.6 & - \\
\hline Peripheral vascular disease & 36.6 & - \\
\hline Cardiac valve calcification & 33.3 & 15 \\
\hline
\end{tabular}

patients, irrespective of the procedure carried out. No long-term pathological fractures were reported. In 18/30 patients -54\%- postoperative cardiovascular events were observed and mortality rate was $23.3 \%$ (Table 4 ). One patient died for abdominal aortic aneurysm rupture, 3 for congestive hearth failure and 3 for myocardial infarction (after a postoperative mean interval time of 27.2 months). One patient also died for a pulmonary cancer.

\section{Medical groupDemographics}

Patient mean age was $55 \pm 11.20$ years, and mean dialysis vintage was $10 \pm 1.96$ years. Mean preoperative iPTH was $102.94 \pm 32.51 \mathrm{pmol} / \mathrm{l}$, and mean serum calcium level was $2.4 \pm 0,65 \mathrm{mmol} / \mathrm{l}$ (Table 1). All patients reported similar clinical symptoms with respect to the surgical group, while cardiovascular disease was found in $20 \%$. Incidence of baseline cardiovascular pathology is reported in Table 2. No case of calciphylaxis was reported. No iron deficiency or external blood loss was observed, while and a mild or moderate anemia $(\mathrm{Hb}$ level $7-<12 \mathrm{gr} / \mathrm{dl}$ ) was present in every case.

\section{Outcomes}

Pathological fractures were not reported. Cardiovascular events are reported in Table 4 . Mortality rate was $15 \%$. Two patients died for cardiovascular disease.

\section{Discussion}

In the present series, PTx did not demonstrate a protective effect against major cardiovascular events, with respect to the incidence observed in the medical control group and also the mortality rate, in patients affected by severe preoperative cardiovascular diseases, was unaffected by surgery (Figure 2), probably because surgery was indicated in $2 \mathrm{HPT}$ advanced stages. Even if preoperative $\mathrm{iPTH}$ serum levels were higher in surgical patients, the compared groups were similar in $2 \mathrm{HPT}$ stage, demographics and preoperative clinical data.

According to the literature, a lower cardiovascular events-risk was expected in patients undergoing surgery. Dramatic reductions in iPTH serum levels, Ca, P, Ca $\times$ $\mathrm{P}$, increase in hematocrit and $\mathrm{Hb}$ levels and, possibly, a significant decrease of ESA needs, in most surgical patients, could explain PTx beneficial effects in HD population. In $2 \mathrm{HPT}$ of CKD-MBD, pathological modifications of mineral metabolism, particularly phosphate (18), worsening atherosclerosis symptoms and favoring arterial stiffness, increase the risk of cardiovascular morbidity and mortality. Liu et al. reported a high prevalence of CKD-MBD in HD patients with coronary arteries disease diagnosed by coronary angiography [27]. Furthermore, uremia is linked to platelet and coagulation dysfunction [28]. Valvular and arterial wall calcifications, depending on common pathogenetic mechanisms 


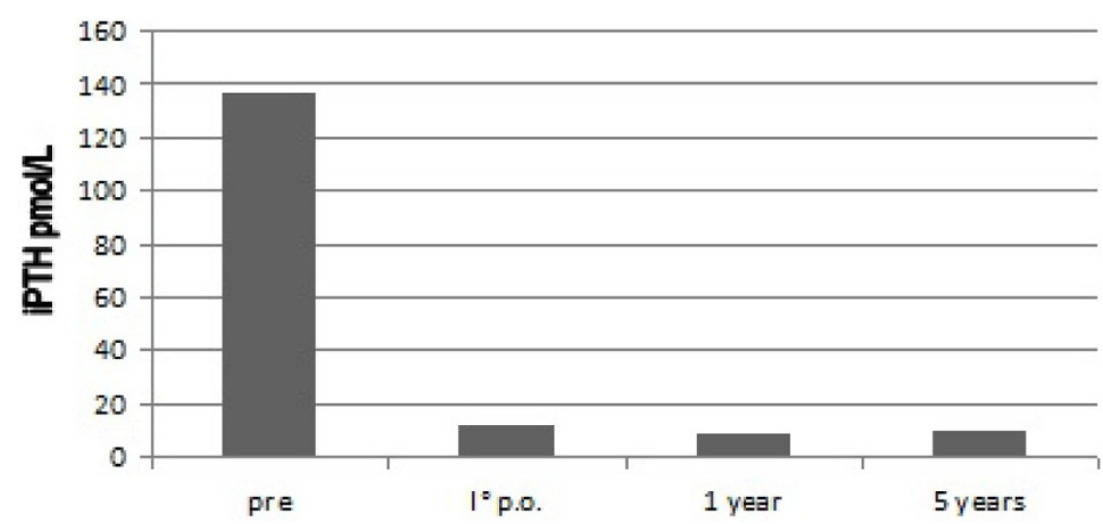

Figure 1 Preoperative, $I^{\circ}$ p.o., 1 year and $\mathbf{5}$ years after surgery mean iPTH levels. [t test $=$ pre vs $I^{\circ}$ p.o.: $p<0,05 ;$ pre vs 1 year: $p<0,05 ;$ pre vs 5 years: $p<0,05]$

[29], left ventricular hypertrophy and hypertension, are the main unfavorable prognostic factors. Regarding the relationship between cardiac valves calcification and mortality rate, US cardiac valves calcifications were present in 5 of the 7 patients who died in our series. Early surgery could offer a remarkable improvement in the quality of life and, possibly, a higher long-term survival rate. Successful surgical treatment often results in a dramatic reduction of iPTH levels, relieving the patient from clinical symptoms, improving nutritional state and immunity, relieving insomnia and improving cognitive function [14,16,30,31]. Moreover, different papers showed that PTX could also improve mortality and cardiovascular morbidity [18-23]. B Dussol et al. [32] reported that PTx is the main cause of postoperative hypoparathyroidism in HD patients, and is associated with a lower mortality risk, suggesting that a more aggressive 2HPT treatment could decrease mortality. Y Tominaga et al. reported, after PTx, an overall 10-year survival rate of $77.6 \%$ in 2000 observed patients [22], higher than that observed in our series (5 years survival of $76.7 \%$ ). According to the present data, PTx did not demonstrate a protective role against cardiovascular events, and did not modify severe effects of unfavorable vascular uremic ossification. Our results were comparable to those finally reported by EVOLVE Trial [9], demonstrating that, similarly to our surgical trial, calcimimetics likewise did not significantly reduce the risk of death or major cardiovascular events in HD patients

Table 3 Ptx postoperative results(\%)

\begin{tabular}{lllll}
\hline & Eupara & Hypopara & Persistence & Relapse \\
\hline l$^{\circ}$ p.o. & 67 & 20 & 13 & - \\
\hline 1 year & 63.3 & 6 & 13 & 17.7 \\
\hline 5 years (23pts) & 60.9 & 4.4 & 13 & 21.68 \\
\hline
\end{tabular}

Ptx = Parathyroidectomy; Eupara = Euparathyroidism; Hypopara $=$ Hypoparathyroidism; $I^{\circ}$ p.o.: 1 day after Ptx affected by moderate-severe 2HPT. Different experimental and clinical studies tried to explain beneficial effects of PTx on cardiovascular outcomes, but they remain unclear [19]. Reductions of iPTH, Ca, P, and increase in serum albumin, hematocrit are the main investigated factors. According to AJ Bleyer et al. [33], PTx may also induce vascular remodeling, but in our series no postoperative regression of cardiovascular calcification was observed. KR Neves et al. [34] suggested that P stimulates the transformation of vascular smooth muscle cells into osteoblast-like cells, creating a promineralization environment. Uremia is associated with a loss of inhibitors of calcification [35] and in addition, parathyroid hormone, acting on vascular system via $\mathrm{PTH} 2$ receptors [36,37], may increase atherosclerosis by stimulating vascular smooth muscle cells collagen production [33], or by increasing receptor of advanced glycation end products (RAGE), monocyte-macrophages cytokines and IL-6 expressions [38]. Thus, PTx, with a low morbidity rate similar to that reported in thyroid surgery [39-47], reducing $\mathrm{iPTH}$ levels [30], may determine a lower cardiovascular complications rate.

The compared groups were similar in 2HPT stage, demographics and preoperative clinical data, but the relatively small number of examined subjects was the main limitation of this retrospective analysis. Moreover,

Table 4 Incidence of cardiovascular events and mortality rate during 60 month follow-up (\%).

\begin{tabular}{lll}
\hline & Surgical group & Medical group \\
\hline Congestive heart failure & 23.3 & 0 \\
\hline Coronary disease & 3.3 & 0 \\
\hline Myocardial infarction & 23.3 & 10 \\
\hline Cerebrovascular accident & 3.3 & 1 \\
\hline Peripheral vascular disease & 6.6 & 0 \\
\hline Mortality rate & 23.3 & 15 \\
\hline
\end{tabular}




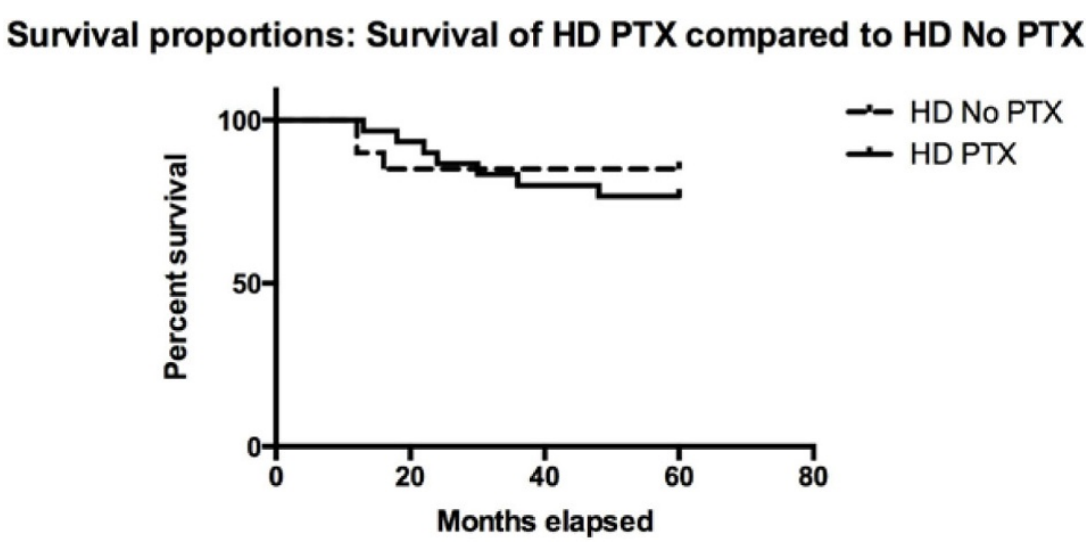

Figure 2 PTx effects on overall survival. The survival curves relative to the medical control group (dotted line) and PTx group (solid line) are depicted. Months elapsed are plotted against percent survival. The log-rank Mantel-Cox test ( $p$ value $=0.5559$ ) and Gehan-Breslow-Wilcoxon test ( $p$ value $=0.6592$ ) are not significant for a difference between the two curves.

it must be considered that calcimimetics were not administered; therefore, the impact of novel therapies is not known.

\section{Conclusions}

Our study supports the following: PTx determined a remarkable improvement of quality of life in all cases. However, the lower expected cardiovascular events rate following PTx, compared to that observed in non-surgical patients, was not confirmed. Moreover, mortality was unaffected by surgery, with a 5 years survival of $76.7 \%$. Therefore, a more aggressive multimodal 2HPT treatment should be suggested. Calcimimetics, as well as early surgery, in unresponsive to medical treatment HD patients, may offer an improved quality of life and possibly a higher long-term survival, only if implemented in 2HPT initial stage. Further studies will be useful to clarify the role of $2 \mathrm{HPT}$ in determining unfavorable cardiovascular outcomes and mortality in HD population.

\section{Abbreviations list}

2 HPT: secondary hyperparathyroidism; CKD-MBD: chronic Kidney disease-mineral bone disorders; PTx: parathyroidectomy; Ca: calcium; P: serum phosphate; iPTH: intact parathyroid hormone; ECG: electrocardiogram; US: ultrasound; ESA: Erythropoiesis Stimulating Agents; ENT: Ear, Nose and Throat; ALP: alkaline phosphatase; CLIA: chemiluminescence immunoassay; TPai: parathyroidectomy with autotransplantation; SEM: standard error of the mean.

\section{Competing interests}

The authors declare that they have no competing interests.

\section{Authors' contributions}

GC: conception, design, and execution of the study; critical revision; analysis and interpretation of data; drafting and editing of the manuscript; given final approval of the version to be published.
AFP: conception, design, and execution of the study; analysis and interpretation of data.

VS: conception, design, and execution of the study; analysis and interpretation of data.

AP: conception, design, and execution of the study; analysis and interpretation of data.

CDP: conception, design, and execution of the study; analysis and interpretation of data.

DI: conception, design, and execution of the study; analysis and interpretation of data.

ES: conception, design, and execution of the study; analysis and interpretation of data.

GC: conception and design, given final approval of the version to be published

LS: conception and design, given final approval of the version to be published.

GD: conception, design, and execution of the study; analysis and interpretation of data; drafting and editing of the manuscript.

\section{Authors' information}

GC: Assistant Professor of Surgery at Second University of Naples AFP: Associate Professor of Nephrology at Second University of Naples VS: Associate Professor of Nephrology at University of Messina AP: Surgical fellow at Second University of Naples CDP: Surgical fellow at Second University of Naples DI: Associate Professor of Biochemistry at Second University of Naples ES: Research Fellow in Nephrology at Second University of Naples GC: Full Professor of Nephrology at Second University of Naples

LS: Full Professor of Surgery at Second University of Naples GD: Associate Professor of Surgery at Second University of Naples

\section{Declaration statement}

Publication of this article was funded by personal funds.

This article has been published as part of BMC Surgery Volume 13 Supplement 2, 2013: Proceedings from the 26th National Congress of the Italian Society of Geriatric Surgery. The full contents of the supplement are available online at http://www.biomedcentral.com/bmcsurg/supplements/ $13 / 52$

\section{Authors' details}

'Department of Anaesthesiologic, Surgical and Emergency Sciences - VII Division of General and Endocrine Surgery-Second University of Naples Italy. ${ }^{2}$ Department of Cardio-thoracic and Respiratory Sciences - First Division of Nephrology - Second University of Naples - Italy. ${ }^{3}$ Papardo Hospital University of Messina-Italy. ${ }^{4}$ Department of Biochemistry and Biophysics "F. Cedrangolo" - Second University of Naples - Italy.

Published: 8 October 2013 


\section{References}

1. Fassbinder W, Brunner FP, Brynger $H$, Ehrich JH, Geerlings W, Raine AE Rizzoni G, Selwood NH, Tufveson G, Wing AJ: Combined report on regular dialysis and transplantation in Europe. Nephrol Dial Transplant 1991, 6(Suppl 1):5-35.

2. Decker PA, Cohen EP, Doffek BSKM, Ashley ME: Subtotal parathyroidectomy in renal failure: still needed after all these years. World J of Surgery 2001, 25:708-712.

3. Young EW, Albert JM, Satayathum S, Goodkin DA, Pisoni RL, Akiba T, Akizawa T, Kurokawa K, Bommer J, Piera L, Port FK: Predictors and consequences of altered mineral metabolism: the Dialysis Outcomes and Practice Patterns Study. Kidney Int 2005, 67(3):1179-87.

4. Conzo G, Perna AF, Napolitano S, Mauriello C, Gambardella C, Satta E, Ciancia G, Papasso GB, Santini L: Partial response to cinacalcet treatment in a 2HPT hemodialysis patient. Case report. Journal of Medical Case Reports 2012.

5. Komaba H, Nakanishi S, Fujimori A, Tanaka M, Shin J, Shibuya K, Nishioka M, Hasegawa $H$, Kurosawa T, Fukagawa M: Cinacalcet effectively reduces parathyroid hormone secretion and gland volume regardless of pretreatment gland size in patients with secondary hyperparathyroidism. Clin J Am Soc Nephrol 2010, 5(12):2305-2314, Epub 2010 Aug 26.

6. Narayan R, Perkins RM, Berbano EP, Yuan CM, Neff RT, Sawyers ES, Yeo FE, Vidal-Trecan GM, Abbott KC: Parathyroidectomy versus cinacalcet hydrochloride-based medical terapy in the management of hyperparathyroidism in ESRD: a cost utility analysis. Am J Kidney Dis 2007, 49(6):801-813.

7. Conzo G, Perna A, Della Pietra C, Esposito D, Nunziata A, Palazzo A, Pizza A Satta E, Sciascia V, Santini L: Role of Parathyroidectomy on anemia control and erythropoiesis-stimulating agent need in Secondary Hyperparathyroidism of Chronic Kidney Disease. A retrospective study in 30 hemodialysis patients. Parathyroidectomy ameliorates anemia Ann Ital Chir 2013, 84(1):25-31.

8. Perna A, Lanza D, Sepe I, Conzo G, Altucci L, Ingrosso D: Altered folate receptor 2 expression in uremic patients on hemodialysis: implications for folate resistance., Nephrology Dialysis Transplantation-First published online: February 24, 2013 pag. 1-10 DOl 10.1093/ndt/gfs510 0156.

9. EVOLVE Trial Investigators, Chertow GM, Block GA, Correa-Rotter R, Drüeke TB, Floege J, Goodman WG, Herzog CA, Kubo Y, London GM, Mahaffey KW, Mix TC, Moe SM, Trotman ML, Wheeler DC, Parfrey PS: Effect of cinacalcet on cardiovascular disease in patients undergoing dialysis. N Engl J Med 2012, 367(26):2482-2494, doi: 10.1056/NEJMoa1205624. Epub 2012 Nov 3.

10. Ganesh SK, Stak AG, Levin NW, Hulbert-Shearon T, Port FK: Association of serum phosphorus and calcium $\times$ phosphorus product, and parathyroid hormone with cardiac mortality risk in chronic hemodialysis patients. J Am Soc Nephrol 2001, 12:2131-2138.

11. Rodriguez M, Caravaca F, Fernandez E, Borrego MJ, Lorenzo V, Cubero J, Martin-Malo A, Betriu A, Jimenez A, Torres A, Felsenfeld AJ: Parathyroid function as a determinant of the response to calcitriol treatment in the hemodialysis patient. Kidney Int 1999, 56(1):306-17.

12. NATIONAL KIDNEY FOUNDATION: K/DOQI clinical practice guidelines for bone metabolism and disease in chronic kidney disease. Am J Kidney Dis 2003, 42(Suppl 4):S127-S129.

13. KDIGO: Clinical Practice Guideline for the Diagnosis, Evaluation, Prevention and Treatment of Chronic Kidney Disease-Mineral and Bone Disorder (CKD-MBD). 2009, 76(Supplement 113).

14. Esposito MG, Cesare CM, De Santo RM, Cice G, Perna AF, Violetti E, Conzo G, Bilancio G, Celsi S, Annunziata F, lannelli S, De Santo NG, Cirillo M, Livrea A: Parathyroidectomy improves the quality of sleep in maintenance hemodialysis patients with severe hyperparathyroidism. J Nephrol 2008, 21(Suppl 13):S92-6.

15. Conzo G, Perna AF, Sinisi AA, Palazzo A, Stanzione F, Della Pietra C, Livrea A Total parathyroidectomy without autotransplantation in the surgical treatment of secondary hyperparathyroidism of chronic kidney disease. J Endocrinol Invest 2012, 35:8-13.

16. De Santo RM, Livrea A, De Santo NG, Conzo G, Bilancio G, Celsi S, Cirillo M: The high prevalence of alexithymia in hemodialyzed patients with secondary hyperparathyroidism unsuppressed by medical therapy is cured by parathyroidectomy. J Ren Nutr 2010, 20(5 Suppl):S64-S70.

17. Tominaga Y, Matsouka S, Sato T: Surgical indications and procedures of parathyroidectomy in patients with chronic kidney disease. Therapeutic Aphresis and Dialysis 2005, 9(1):44-47.
18. Costa-Hong V, Jorgetti V, Gowdak LH, Moyses RM, Krieger EM, De Lima JJ: Parathyroidectomy reduces cardiovascular events and mortality in renal yperparathyroidism. Surgery 2007, 142(5):699-703.

19. Sharma J, Raggi $P$, Kutner N, Bailey J, Zhang $R$, Huang $Y$, Herzog CA Weber C: Improved long-term survival of dialysis patients after near-total parathyroidectomy. J Am Coll Surg 2012, 214(4):400-407.

20. Fotheringham J, Balasubramanian SP, Harrison B, Wilkie M: Postparathyroidectomy parathyroid hormone levels: the impact on patient survival - a single-centre study in a stage 5 chronic kidney disease population. Nephron Clin Pract 2011, 119(2):c113-c120, Epub $2011 \mathrm{Jul} 8$.

21. Iwamoto N, Sato N, Nishida M, Hashimoto T, Kobayashi H, Yamasaki S, Ono T, Nishimura M, Tokoro T, Sakoda C, Murakawa M, Okino K, Okamoto Y, Imai R, Adachi N, Ninomiya K, Mabuchi H, Koyama M, Nakanouchi T, Iseki K: Total parathyroidectomy improves survival of hemodialysis patients with secondary hyperparathyroidism. J Nephrol 2011, 0. doi: 10.5301/jn.5000056.

22. Tominaga $Y$, Matsuoka S, Uno N: Surgical and medical treatment of secondary hyperparathyroidism in patients on continuous dialysis. World J Surg 2009, 33(11):2335-42.

23. Nanasato M, Goto N, Isobe S, Unno K, Hirayama H, Sato T, Matsuoka S, Nagasaka T, Tominaga Y, Uchida K, Murohara T: Restored cardiac conditions and left ventricular function after parathyroidectomy in a hemodialysis patient. Parathyroidectomy improves cardiac fatty acid metabolism assessed by 123I-BMIPP. Circ J 2009, 73(10):1956-1960, Epub 2009 Jan 27.

24. Bellasi A, Ferramosca E, Ratti C, Block G, Raggi P: Cardiac valve calcification is a marker of vascular disease in prevalent hemodialysis patients. J Nephrol 2012, 25(02):211-218.

25. National Clinical Guideline Centre (UK): Anaemia Management in Chronic Kidney Disease: Rapid Update 2011. London: Royal College of Physicians (UK). 2011, National Institute for Health and Clinical Excellence: Guidance.

26. Wong M, Tei C, Shah PM: Sensitivity and specificity of two-dimensional echocardiography in the detection of valvular calcification. Chest 1983, 84:423-427.

27. Liu H, Yan L, Ma GS, Zhang LP, Gao M, Wang YL, Wang SP, Liu BC: Association of chronic kidney disease and coronary artery disease in 1,010 consecutive patients undergoing coronary angiography. J Nephrol 2012, 25(2):219-224

28. Onoyama K, Ibayashi S, Nanishi F, Okuda S, Oh Y, Hirakata H, Nishimura Y, Fujishima M: Cerebral hemorrhage in patients on maintenance hemodialysis. CT analysis of 25 cases. Eur Neurol 1987, 26(3):171-175.

29. Moe SM, O'Neill KD, Duan D, Ahmed S, Chen NX, Leapman SB, Fineberg N, Kopecky K: Medial artery calcification in ESRD patients is associated with deposition of bone matrix proteins. Kidney Int 2002, 61(2):638-647.

30. Conzo G, Perna A, Avenia N, de Santo RM, Della Pietra C, Palazzo A, Sinisi AA, Stanzione F, Santini L: Evaluation of "putative" role of intraoperative intact parathyroid hormone assay during parathyroidectomy for secondary hyperparathyroidism. A retrospective study on 35 consecutive patients., Endocrine DOI 10.1007/s 12020-0129648-5 Published on line. 16 march 2012-03-25.

31. De Santo RM, Esposito MG, Cesare CM, Cice G, Perna A, Violetti E, Conzo G, Bilancio G, Celsi S, Cirillo M, Livrea A: High prevalence of sleep disorders in hemodialyzed patients requiring parathyroidectomy. J Ren Nutr 2008, 18(1):52-55.

32. Dussol $B$, Morand $P$, Martinat $C$, Lombard $E$, Portugal $H$, Brunet $P$, Berland $Y$ : Influence of parathyroidectomy on mortality in hemodialysis patients: aprospective observational study. Ren Fail 2007, 29:579-586.

33. Bleyer AJ, Burkart J, Piazza M, Russell G, Rohr M, Carr JJ: Changes in cardiovascular calcification after parathyroidectomy in patients with ESRD. Am J Kidney disease 2005, 46:464-469.

34. Neves KR, Graciolli FG, dos Reis LM, Graciolli RG, Neves CL, Magalhães AO, Custódio MR, Batista DG, Jorgetti V, Moysés RM: Vascular calcification: contribution of parathyroid hormone in renal failure. Kidney Int 2007, 71(12):1262-1270, Epub 2007 Apr 4.

35. Ketteler M, Wenstenfeld R, Schlieper G, Brandenburg V: Pathogenesis of vascular calcification in dialysis patients. Clin Exp Nephrol 2005, 9:265-270.

36. Murray TM, Rao LG, Divieti P, Bringhurst FR: parathyroid hormone secretion and action: evidence for discrete receptors for the carboxylterminal region and related biological actions of carboxyl-terminal ligands. Endocr rev 2005, 26:78-113. 
37. Jüppner $H$, Abou-Samra $A B$, Freeman $M$, Kong XF, Schipani E, Richards $J$ Kolakowski LF Jr, Hock J, Potts JT Jr, Kronenberg HM, et al: A G proteinlinked receptor for parathyroid hormone and parathyroid hormonerelated peptide Science. 1991, 254(5034):1024-1026.

38. Rashid G, Bernheim J, Green J, Benchetrit S: Parathyroid hormone stimulates endothelial expression of atherosclerotic parameters through protein kinase pathways. Am J Physiol Renal Physiol 2007, 292(4): F1215-F1218, Epub 2006 Dec 26.

39. Conzo G, Pasquali D, Bellastella G, Esposito K, Carella C, De Bellis A, Docimo G, Klain M, lorio S, Napolitano S, Palazzo A, Pizza A, Sinisi A, Zampilla E, Bellastella A, Santini L: Total thyroidectomy, without prophylactic central lymph node dissection, in the treatment of differentiated thyroid cancer. Clinical retrospective study on 221 cases. Endocrine DOI 10.1007/s12020-013-9877-2 2013.

40. Cirocchi R, Boselli C, Guarino S, Sanguinetti A, Trastulli S, Desiderio J, Santoro A, Rondelli F, Conzo G, Parmeggiani D, Noya G, De Toma G, Avenia N: Total thyroidectomy with ultrasonic dissector for cancer: multicentric experience. World J Surg Oncol 2012, 10:70.

41. De Bellis A, Conzo G, Cennamo G, Pane E, Bellastella G, Colella C, lacovo AD, Paglionico VA, Sinisi AA, Wall JR, Bizzarro A, Bellastella A: Time course of Graves' ophthalmopathy after total thyroidectomy alone or followed by radioiodine therapy: a 2-year longitudinal study. Endocrine 2012, 41:320-6.

42. Docimo G, Tolone S, Pasquali D, Conzo G, D'Alessandro A, Casalino G, Gili S, Brusciano L, Gubitosi A, del Genio G, Ruggiero R, Docimo L: Role of pre and post-operative oral calcium and vitamin $D$ supplements in prevention of hypocalcemia after total thyroidectomy. G Chir 2012, 33(11-12):1-5.

43. Parmeggiani D, De Falco M, Avenia N, Sanguinetti A, Fiore A, Docimo G Ambrosino P, Madonna I, Peltrini R, Parmeggiani U: Nerve sparing sutureless total thyroidectomy. Preliminary study. Ann Ital Chir 2012. 83(2):91-96, Mar-Apr, PMID: 22462326.

44. Docimo G, Tolone S, Gili S, d'Alessandro A, Casalino G, Brusciano L, Ruggiero R, Docimo L: Minimally Invasive Thyroidectomy (MIT): indications and results. Ann Ital Chir 2012, doi:pii: S0003469X12020386.

45. Avenia N, Sanguinetti A, Cirocchi R, Docimo G, Ragusa M, Ruggiero R, Procaccini E, Boselli C, D'Ajello F, Parmeggiani D, Rosato L, Sciannameo F, De Toma G, Noya G: Antibiotic prophylaxis in thyroid surgery: A preliminary multicentric italian experience. 2009 Ann Surg Innov Res 3:10, Aug 5.

46. D'Ajello F, Cirocchi R, Docimo G, Catania A, Ardito G, Rosato L, Avenia N Thyroidectomy with ultrasonic dissector: a multicentric experience. 2010 G Chir 31(6-7):289-292.

47. Gervasi R, Orlando G, Lerose MA, Amato B, Docimo G, Zeppa P, Puzziello A: Thyroid surgery in geriatric patients: a literature review. BMC Surg 2012 12(Suppl 1):S16.

doi:10.1186/1471-2482-13-S2-S4

Cite this article as: Conzo et al:: Impact of parathyroidectomy on cardiovascular outcomes and survival in chronic hemodialysis patients with secondary hyperparathyroidism. A retrospective study of 50 cases prior to the calcimimetics era. BMC Surgery 2013 13(Suppl 2):S4.

\section{Submit your next manuscript to BioMed Central and take full advantage of:}

- Convenient online submission

- Thorough peer review

- No space constraints or color figure charges

- Immediate publication on acceptance

- Inclusion in PubMed, CAS, Scopus and Google Scholar

- Research which is freely available for redistribution

Submit your manuscript at www.biomedcentral.com/submit
Biomed Central 